\title{
The Inverse Split and Non-split Domination in Graphs
}

\author{
K. Ameenal Bibi \\ Department of Mathematics \\ Dhanabagiyam Krishnaswamy Mudaliar College \\ for Women (Autonomous), Vellore -1 .
}

\author{
R.Selvakumar \\ Department of Mathematics \\ VIT University, Vellore -14
}

\begin{abstract}
In this paper, we define the notions of inverse split and non split domination in graphs. We get many bounds on inverse split and non split domination numbers. Nordhaus-Gaddum type results are also obtained for these new parameters.
\end{abstract}

Keywords: Independent set, dominating set, split dominating set, non-split dominating set, inverse split dominating set, inverse non-split dominating set, inverse split and non-split domination numbers.

\subsection{INTRODUCTION}

Kulli V.R. et al introduced the concept of split domination and non-split domination in graphs. Kulli V.R. et al introduced the concept of Inverse domination in graphs. Let $\mathrm{G}=(\mathrm{V}, \mathrm{E})$ be a simple, finite, undirected, connected graph. Any undefined term in this paper may be found in Haynes T. W et al (1998). A nonempty set $\mathrm{D} \subseteq \mathrm{V}$ of a graph $\mathrm{G}$ is a dominating set of $\mathrm{G}$ if every vertex in $\mathrm{V}$-D is adjacent to some vertex in $\mathrm{D}$. The domination number $\gamma(G)$ is the minimum cardinality taken over all the minimal dominating sets of $\mathrm{G}$. Let $\mathrm{D}$ be the minimum dominating set of $\mathrm{G}$. If $\mathrm{V}$-D contains a dominating set $\mathrm{D}^{\prime}$ then $\mathrm{D}^{\prime}$ is called the Inverse dominating set of G w.r.to D. The Inverse dominating number $\gamma^{\prime}(\mathrm{G})$ is the minimum cardinality taken over all the minimal inverse dominating sets of $\mathrm{G}$. A dominating set $\mathrm{D}$ of $\mathrm{G}$ is a connected dominating set if the induced subgraph $\langle\mathrm{D}\rangle$ is connected [Sampathkumar E. and Walikar H.B. (1979)]. The connected domination number $\gamma_{c}(G)$ is the minimum cardinality of a connected dominating set. Unless stated, the graph $\mathrm{G}$ has $\mathrm{n}$ vertices and $\mathrm{m}$ edges. A dominating set $\mathrm{D} \subseteq \mathrm{V}$ of a graph $\mathrm{G}$ is a split (non-split) dominating set if the induced subgraph $\langle\mathrm{V}-\mathrm{D}\rangle$ is disconnected (connected). The split (non-split) domination number $\gamma_{s}(\mathbf{G})$ $\left(\gamma_{\mathbf{n s}}(\mathbf{G})\right)$ is the minimum cardinality of a split (non-split) dominating set.

The purpose of this paper is to introduce the concept of Inverse split domination and Inverse non-split domination in graphs. Let $\mathrm{D}^{\prime}$ be the minimum Inverse dominating set of $\mathrm{G}$ w.r.to. D. Then $\mathrm{D}^{\prime}$ is called an Inverse split (non-split) dominating set of $\mathrm{G}$ if the induced subgraph $\left\langle\mathrm{V}-\mathrm{D}^{\prime}\right\rangle$ is disconnected (connected). The inverse split (non-split) domination number is denoted by $\gamma_{\mathrm{s}}{ }^{\prime}(\mathrm{G})\left(\gamma^{\prime}{ }_{\text {ns }}(\mathrm{G})\right)$ and it is the minimum cardinality taken over all the minimal inverse split (non-split) dominating sets of $\mathrm{G}$. In this paper, many bounds on $\gamma_{s}^{\prime}(G)$ and $\gamma_{n s}^{\prime}(G)$ are obtained and their exact values for some standard graphs are found. Also their relationships with other parameters are investigated. Nordhaus-Gaddum type results are also obtained for these parameters. with \# $\gamma(\mathrm{G})$

- set is the set of all vertices in a dominating set $\gamma^{\prime}$ - set is the set of all vertices in an inverse dominating set with \# $\gamma^{\prime}(\mathrm{G})$ $\gamma_{c}-$ set is the set of all vertices in a connected dominating set with \# $\gamma_{c}(\mathrm{G})$ set with $\# \gamma_{\mathrm{s}}(\mathrm{G})$

$\gamma_{s}$ - set is the set of all vertices in a split dominating

$\gamma_{s}^{\prime}$ - set is the set of all vertices in an inverse split dominating set with $\# \gamma_{s}^{\prime}(\mathrm{G})$

$\gamma_{\mathrm{ns}}$ - set is the set of all vertices in a non-split dominating set with \# $\gamma_{\mathrm{ns}}(\mathrm{G})$

$\gamma^{\prime}{ }_{n s}$ - set is the set of all vertices in an inverse nonsplit dominating set with \# $\gamma_{\text {ns }}^{\prime}(\mathrm{G})$

\subsection{RESULTS AND BOUNDS}

\subsubsection{Observation and Results}

Here we observed the exact values of $\gamma_{s}{ }_{s}(G)$ and $\gamma^{\prime}{ }_{n s}(\mathrm{G})$ for some standard graphs and proved some standard results.

\section{(a) Observation}

(i) For any complete graph $\mathrm{K}_{\mathrm{n}}$ with $\mathrm{n} \geq 2$ vertices, $\gamma_{\mathrm{s}}^{\prime}\left(\mathrm{K}_{\mathrm{n}}\right)=0 ; \gamma_{\mathrm{ns}}^{\prime}\left(\mathrm{K}_{\mathrm{n}}\right)=1$

(ii) For any cycle $C_{n}$ with $n \geq 3$, $\gamma_{\mathrm{s}}^{\prime}\left(\mathrm{C}_{\mathrm{n}}\right)=\left\lceil\frac{\mathrm{n}}{3}\right\rceil ; \gamma^{\prime}{ }_{\mathrm{ns}}\left(\mathrm{C}_{\mathrm{n}}\right)=0$

\section{Example 1.2.2}

Consider the following graph in figure 1.

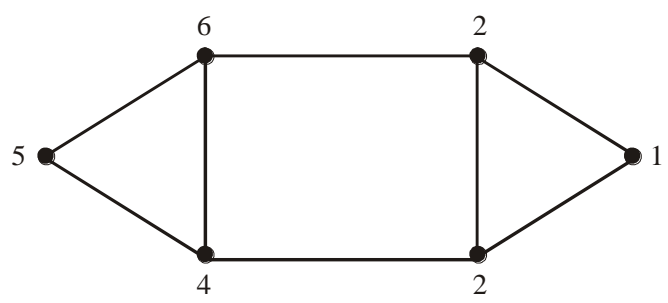

Graph G : Figure 1.

Here $D=\{2,4\}, \quad D^{\prime}=\{1,5\}, V-D^{\prime}=\{2,3,4,6\}$

$\gamma(\mathrm{G})=2$

$\gamma^{\prime}(\mathrm{G})=2$

$\gamma^{\prime}{ }_{\text {ns }}(\mathrm{G})=2$

When $\mathrm{D}=\{1,5\}, \quad \mathrm{D}^{\prime}=\{2,4\}, \mathrm{V}-\mathrm{D}^{\prime}=\{1,3,5,6\}$

Here $\quad \gamma(\mathrm{G})=2$

$\gamma^{\prime}(\mathrm{G})=2 \quad \gamma_{\mathrm{s}}^{\prime}(\mathrm{G})=2$

Theorem 1.2.3.: For any graph $\mathrm{G}$,

$$
\begin{aligned}
& \gamma^{\prime}(\mathbf{G}) \leq \gamma_{\mathrm{s}}{ }^{\prime}(\mathbf{G}) \\
& \gamma^{\prime}(\mathbf{G}) \leq \gamma^{\prime}{ }_{\mathrm{ns}}(\mathbf{G})
\end{aligned}
$$




\section{Proof}

Since every inverse split dominating set of $G$ is an inverse dominating set of G, we have $\gamma^{\prime}(\mathbf{G}) \leq \gamma_{s}^{\prime}(\mathbf{G})$.

Similarly, every inverse non-split dominating set of $\mathrm{G}$ is an inverse dominating set of $\mathrm{G}$, we have $\gamma^{\prime}(\mathbf{G}) \leq \boldsymbol{\gamma}^{\prime}{ }_{\mathrm{ns}}(\mathbf{G})$.

Theorem 1.2.4.: For any graph G,

$$
\gamma^{\prime}(\mathrm{G}) \leq \min \left\{\gamma_{\mathrm{s}}^{\prime}(\mathrm{G}), \gamma_{\mathrm{ns}}^{\prime}(\mathrm{G})\right\}
$$

\section{Proof}

Since every inverse split dominating set and every inverse non-split dominating set of $G$ are the inverse dominating sets of $\mathrm{G}$, we have $\gamma^{\prime}(\mathbf{G}) \leq \gamma^{\prime}$ s $(\mathbf{G})$ and $\gamma^{\prime}(\mathbf{G}) \leq \gamma^{\prime}$ ns (G) and hence $\gamma^{\prime}(\mathrm{G}) \leq \min \left\{\gamma_{\mathrm{s}}^{\prime}(\mathrm{G}), \gamma_{\mathrm{ns}}^{\prime}(\mathrm{G})\right\}$.

\section{Theorem 1.2.5.}

Let $\mathrm{T}$ be a tree such that any two adjacent cut vertices $\mathrm{u}$ and $\mathrm{v}$ with atleast one of $\mathrm{u}$ and $\mathrm{v}$ is adjacent to an end vertex then

$$
\gamma^{\prime}(\mathrm{T})=\gamma_{\mathrm{s}}^{\prime}(\mathrm{T})
$$

\section{Proof}

Let $\mathrm{D}^{\prime}$ be a $\gamma^{\prime}$-set of $\mathrm{T}$, then we consider the following two cases:

\section{Case (i)}

Suppose that atleast one of $\mathrm{u}, \mathrm{v} \in \mathrm{D}^{\prime}$, then $\left\langle\mathrm{V}-\mathrm{D}^{\prime}\right\rangle$ is disconnected with atleast one vertex. Hence $\mathrm{D}^{\prime}$ is a $\gamma_{\mathrm{s}}^{\prime}$-set of $\mathrm{T}$. Thus the theorem is true.

\section{Case (ii)}

Suppose $u, v \in V-D^{\prime}$. Since there exists an end vertex $\omega$ adjacent to either $u$ or $v$ say $u$, it implies that $\omega \in \mathrm{D}^{\prime}$. Thus it follows that $\mathrm{D}^{\prime \prime}=\mathrm{D}^{\prime}-\{\omega\} \cup\{\mathrm{u}\}$ is a $\gamma^{\prime}$-set of $\mathrm{T}$.

Hence by case(i), the theorem is true.

Theorem 1.2.6 : For any tree $\mathrm{T}$,

$$
\gamma_{n s}^{\prime}(T)=n-p
$$
vertices.

where $\mathrm{p}$ is the number of vertices adjacent to end

Theorem 1.2.7 : For any graph G, vertices of $\mathrm{G}$.

$$
\gamma_{\mathrm{ns}}^{\prime}(\mathrm{G}) \leq \mathrm{n}-\delta(\mathrm{G})
$$

where $\delta(\mathrm{G})$ is the minimum degree among the

Note 1.2.8.

For any tree $\mathrm{T}, \delta(\mathrm{T})=1$

Hence $\gamma_{n s}^{\prime}(T) \leq n-1$

\section{Remark 1.2.9}

We obtained the relationship between $\gamma_{n s}^{\prime}(G)$ and $\gamma_{n s}^{\prime}(H)$ where $\mathrm{H}$ is any connected spanning subgraph of $\mathrm{G}$. Similar result for $\gamma_{s}^{\prime}(\mathrm{G})$ and $\gamma_{\mathrm{s}}^{\prime}(\mathrm{H})$.
If $\mathrm{H}$ is any connected Spanning subgraph of $\mathrm{G}$ then $\gamma^{\prime}(\mathrm{G}) \leq \gamma^{\prime}(\mathrm{H})$

\section{Theorem 1.2.10}

Let $\mathrm{G}$ be a graph which is not a cycle with atleast 5 vertices. Let $\mathrm{H}$ be a connected spanning subgraph of $\mathrm{G}$ then
(i) $\gamma_{\mathrm{s}}^{\prime}(\mathrm{G}) \leq \gamma_{\mathrm{s}}^{\prime}(\mathrm{H})$
(ii) $\gamma_{n s}^{\prime}(\mathrm{G}) \leq \gamma_{\mathrm{ns}}^{\prime}(\mathrm{H})$

\section{Proof}

Since $\mathrm{G}$ is connected then any spanning tree $\mathrm{T}$ of $\mathrm{G}$ is minimally connected subgraph of G such that $\gamma_{s}^{\prime}(\mathrm{G}) \leq \gamma_{\mathrm{s}}^{\prime}(\mathrm{T}) \leq$ $\gamma_{s}(\mathrm{H})$

In a similar way, $\gamma_{n s}^{\prime}(G) \leq \gamma_{n s}^{\prime}(T) \leq \gamma_{n s}^{\prime}(H)$

Hence the proof.

\section{(b) BOUNDS ON $\gamma_{\mathrm{s}}^{\prime}(G)$ AND $\gamma_{\mathrm{ns}}^{\prime}(G)$}

\section{Theorem 1.2.11}

Let $\mathrm{G}$ be any graph of order $\geq 3$. Then

(i) $\gamma_{s}^{\prime}(\mathrm{G}) \leq \mathrm{n}-1$ when $\mathrm{G}$ is a $\mathrm{K}_{4}$ - free graph

(ii) $\gamma_{n s}^{\prime}(\mathrm{G}) \leq \mathrm{n}-2$

where $\mathrm{n}$ is the number of vertices

\section{Proof}

(i) Let $\mathrm{D}^{\prime}$ be an inverse split dominating set of $\mathrm{G}$. Then, we have $\mathrm{D}^{\prime}$ is an inverse dominating set of G. This implies that, for every vertex $\mathrm{v} \in \mathrm{V}-\mathrm{D}^{\prime}$, $\mathrm{N}_{\mathrm{G}}(\mathrm{v}) \cap \mathrm{D}^{\prime}=\phi$. It means that $\mathrm{D}^{\prime}$ is an inverse dominating set in G-v. To prove the required result, it is enough to prove that the induced subgraph $\left\langle\mathrm{V}-\mathrm{D}^{\prime}\right\rangle_{\mathrm{G}-\mathrm{v}}$ is disconnected. By assumption, the induced subgraph $\left\langle\mathrm{V}-\mathrm{D}^{\prime}\right\rangle_{\mathrm{G}}$ is disconnected implies that $\mathrm{G}$ is a $\mathrm{K}_{4}$ - free graph and every path in $\left\langle\mathrm{V}-\mathrm{D}^{\prime}\right\rangle$ contains no vertex from $D^{\prime}$. Also, the removal of the vertex $v$ from $G$ does not change the above relationship and hence the induced subgraph $\left\langle\mathrm{V}^{-\mathrm{D}^{\prime}}\right\rangle_{\mathrm{G}-\mathrm{v}}$ is also disconnected. Thus, $\gamma_{s}^{\prime}(\mathrm{G}) \leq \mathrm{n}-1$ where $\mathrm{n}$ is the number of vertices of $\mathrm{G}$.

(ii) Since $\mathrm{G}$ is connected, there is a spanning tree $\mathrm{T}$ of $\mathrm{G}$ with (n-1) vertices. If $\mathrm{v}$ is a pendant vertex of $\mathrm{T}$ then ( $n-2)$ vertices of $T$ other than $v$ form a minimal inverse non-split dominating set of $G$, hence $\gamma_{n s}^{\prime}(\mathrm{G}) \leq \mathrm{n}-2$.

\section{Theorem 1.2.12}

If $\mathrm{T}$ is a tree which is not a star then $\gamma_{\mathrm{ns}}^{\prime}(\mathrm{T}) \leq \mathrm{n}-2 \forall$ $\mathrm{n} \geq 3$.

\section{Proof:}

Since $\mathrm{T}$ is not a star, there exists two adjacent cut vertices $u$ and $v$ with degree $u$ and degree $v \geq 2$. This implies that $\mathrm{V}-\{\mathrm{u}, \mathrm{v}\}$ is an Inverse non-split dominating set of $\mathrm{T}$. Thus the theorem is true. 


\subsection{CHARACTERIZATION AND NORDHAUS - GADDUM TYPE RESULTS}

(a) Characterization of Minimal Inverse Non-split dominating set

\section{Theorem 1.3.1}

An inverse non-split dominating set $\mathrm{D}^{\prime}$ of $\mathrm{G}$ is minimal if and only if for each vertex $\mathrm{v} \in \mathrm{D}^{\prime}$, one of the following conditions is satisfied.

(i) There exists a vertex $u \in V$-D' such that

$$
\mathrm{N}(\mathrm{u}) \cap \mathrm{D}^{\prime}=\{\mathrm{v}\}
$$

(ii) $\mathrm{v}$ is not an isolated vertex in $\left\langle\mathrm{D}^{\prime}\right\rangle$

(iii) $\mathrm{u}$ is not an isolated vertex in $\left\langle\mathrm{V}-\mathrm{D}^{\prime}\right\rangle$

\section{Proof} set of G.

Suppose $\mathrm{D}^{\prime}$ is a minimal inverse non-split dominating

\section{Suppose the contrary.}

That is, if there exists a vertex $\mathrm{v} \in \mathrm{D}^{\prime}$ such that $\mathrm{v}$ does not satisfy any of the given conditions, then by theorem given by Kulli V .R and Janakiram. B (2000), there exists an inverse dominating set $\mathrm{D}^{\prime \prime}=\mathrm{D}^{\prime}-\{\mathrm{v}\}$ such that the induced subgraph $<\mathrm{V}$ $\mathrm{D}^{\prime \prime}>$ is connected. This implies that $\mathrm{D}^{\prime \prime}$ is an inverse non-split dominating set of $G$ contradicting the minimality of $\mathrm{D}^{\prime}$. Therefore, the condition is necessary.

Sufficiency follows from the given conditions.

\section{(b) Nordhaus-Gaddum Type results}

\section{Theorem 1.3.2} isolates. Then,

Let $\mathrm{G}$ be a graph such that both $\mathrm{G}$ and $\overline{\mathrm{G}}$ have no

i) $\gamma_{\mathrm{s}}^{\prime}(\mathrm{G})+\gamma_{\mathrm{s}}^{\prime}(\overline{\mathrm{G}}) \leq 2(\mathrm{n}-1)$

ii) $\gamma_{\mathrm{s}}^{\prime}(\mathrm{G}) \cdot \gamma_{\mathrm{s}}^{\prime}(\overline{\mathrm{G}}) \leq(\mathrm{n}-1)^{2}$.

\section{Proof}

The results follow from Theorem 2.2.11(i)

\section{Theorem 1.3.3}

Then

Let $\mathrm{G}$ and $\overline{\mathrm{G}}$ be connected complementary graphs.

$$
\begin{aligned}
& \text { i) } \quad \gamma_{\mathrm{ns}}^{\prime}(\mathrm{G})+\gamma_{\mathrm{ns}}^{\prime}(\overline{\mathrm{G}}) \leq 2(\mathrm{n}-2) \\
& \text { ii) } \gamma_{\mathrm{ns}}^{\prime}(\mathrm{G}) \cdot \gamma_{\mathrm{ns}}^{\prime}(\overline{\mathrm{G}}) \leq(\mathrm{n}-2)^{2} .
\end{aligned}
$$

\section{Proof}

The results follow from Theorem 1.2.11 (ii).

\section{Remark 1.3.4}

In a similar way, the edge-analog of the above two inverse parameters is studied meticulously. These parameters are referred as co-edge split dominating set (CESD-set) and coedge non-split dominating set (CENSD-set) respectively.

\subsection{MAIN RESULTS IN CO-EDGE SPLIT AND NON-SPLIT DOMINATING SETS}

\section{Definition 1.4.1}

A co-edge split dominating set (CESD-set) of a graph $\mathrm{G}=(\mathrm{V}, \mathrm{E})$ is a co-edge dominating set $\mathrm{X}$ of a graph $\mathrm{G}$ such that the edge induced subgraph $\langle E \backslash X\rangle$ is disconnected and the co-edge split domination number $\gamma_{c s}^{\prime}(G)$ is the minimum cardinality of the minimal co-edge split dominating set of $\mathrm{G}$.

\section{Definition 1.4.2}

A co-edge dominating set $\mathrm{X}$ of a graph $\mathrm{G}=(\mathrm{V}, \mathrm{E})$ is a co-edge non-split dominating set (CENSD-set) if the edge induced subgraph $\langle E \backslash X\rangle$ is connected. The co-edge non-split domination number is denoted by $\gamma_{\text {cens }}(G)$ and it is the minimum cardinality of the minimal co-edge non-split dominating set of $\mathrm{G}$

\section{Note 1.4.3}

The concept of edge domination was introduced by Mitchell and Hedetniemi (1977) and further studied by Arumugam and Velammal (1988). A subset of $X$ of $E$ is an edge dominating set (ED-set) of $G$ if every edge in $E \backslash X$ is adjacent to some edge in $\mathrm{X}$. The minimum cardinality of the minimal ED-set of $\mathrm{G}$ is called the edge domination number of $\mathrm{G}$ and is denoted by $\gamma^{\prime}(\mathrm{G})$ (Mitchell and Hedetniemi, 1977).

Let $\mathrm{X}$ be the minimum edge dominating set of $\mathrm{G}$. If $\mathrm{E}$ $\checkmark X$ contains an edge dominating set $X_{1}$, then $X_{1}$ is called the complementary edge dominating set (or) co-edge dominating set of $G$ with respect to $X$. The co-edge domination number is the minimum cardinality of the minimal co-edge dominating set of $\mathrm{G}$.

An edge dominating set $\mathrm{X}$ of $\mathrm{G}$ is called a connected edge dominating set (CED-set) if the edge induced subgraph $\langle\mathrm{X}\rangle$ is connected. The minimum cardinality of a minimal CED-set of $\mathrm{G}$ is called the connected edge domination number and it is denoted by $\gamma_{c}^{\prime}(\mathrm{G})$. (Kulli and Sigarkanti, 1988).

We call a set of edges a $\gamma^{\prime}$-set if it is an ED-set with cardinality $\gamma^{\prime}(\mathrm{G})$. In a similar way, $\gamma_{\mathrm{c}}^{\prime}$-set, $\gamma_{\text {ces }}^{\prime}$-set and $\gamma_{\text {cens-set }}^{\prime}$ are defined. The degree of an edge $\mathrm{e}=\mathrm{uv}$ of $\mathrm{G}$ is defined by $\operatorname{deg}(\mathrm{e})=\operatorname{deg}(\mathrm{u})+\operatorname{deg}(\mathrm{v})-2$. The maximum and minimum edge degree of the graph $\mathrm{G}$ is denoted by $\Delta^{\prime}(\mathrm{G})$ and $\delta^{\prime}(\mathrm{G})$ respectively. An edge is said to be isolated if its degree is 0 and an edge is called a pendant edge if anyone of its and vertex has degree one. The open neighbourhood of an edge e in a graph $\mathrm{G}$ is denoted by $\mathrm{N}_{\mathrm{G}}(\mathrm{e})$ and it is the set of all edges adjacent to e in G. The closed neighbourhood of an edge e in a graph $G$ is denoted by $\mathrm{N}_{\mathrm{G}}[\mathrm{e}]$ and it is defined as $\mathrm{N}_{\mathrm{G}}[\mathrm{e}]=\mathrm{N}_{\mathrm{G}}(\mathrm{e}) \cup\{\mathrm{e}\}$.

\section{Example 1.4.4}

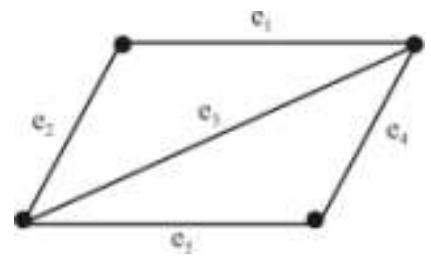

Graph G : Figure 2. 
For this graph $\mathrm{G}, \mathrm{X}_{1}=\left\{\mathrm{e}_{1}, \mathrm{e}_{5}\right\}$ is a CESD-set and hence $\gamma_{c s}^{\prime}(G)=2$.

Let $\gamma^{\prime}(\mathrm{G})-$ set and $\gamma_{\text {cs }}^{\prime}(\mathrm{G})$-set be respectively denote the minimum ED-set and minimum CESD-set of G. We note that $\gamma_{\mathrm{cs}}^{\prime}(\mathrm{G})$-sets exist if the graph is not complete and either contains a non-complete component or contains atleast two non-trivial components. For convenience we will assume that $\mathrm{G}$ contains a CESD-set. Further we also note that in a disconnected graph any $\gamma^{\prime}(\mathrm{G})$-set is $\gamma_{c s}^{\prime}(\mathrm{G})$-set.

\section{Example 1.4.5}

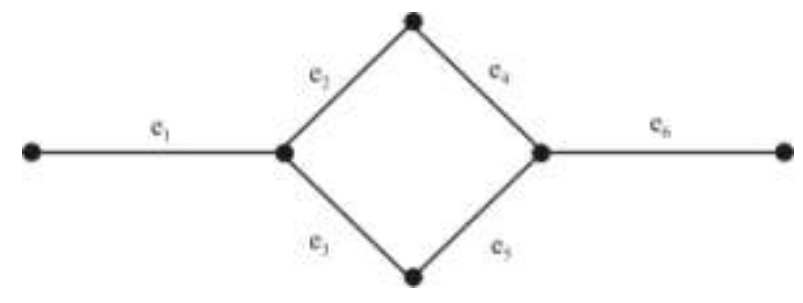

Graph G : Figure 3.

For the above graph $\mathrm{G}, \mathrm{X}=\left\{\mathrm{e}_{2}, \mathrm{e}_{4}\right\}$ is a minimum CENSD-set and hence $\gamma_{\text {cens }}^{\prime}(G)=2$.

We started with some elementary results.

\section{Theorem 1.4.6}

For any graph $\mathrm{G}$,

$\gamma^{\prime}(\mathrm{G}) \leq \gamma_{\text {cens }}^{\prime}(\mathrm{G})$

\section{Proof}

Since every CENSD-set of $\mathrm{G}$ is an ED-set of $\mathrm{G}$ and hence the result.

\section{Theorem 1.4.7}

For any graph $\mathrm{G}$

$\gamma^{\prime}(\mathrm{G}) \leq \min \left\{\gamma_{\text {ces }}^{\prime}(\mathrm{G}), \gamma_{\text {cens }}^{\prime}(\mathrm{G})\right\}$

\section{Proof}

Since every CESD-set and CENSD-set of G are edset of $\mathrm{G}$, which gives

$$
\begin{aligned}
& \gamma^{\prime}(\mathrm{G}) \leq \gamma_{\text {ces }}^{\prime}(\mathrm{G}) \text { and } \gamma^{\prime}(\mathrm{G}) \leq \gamma_{\text {cens }}^{\prime}(\mathrm{G}) \\
& \text { and hence } \gamma^{\prime}(\mathrm{G}) \leq \min \left\{\gamma_{\text {ces }}^{\prime}(\mathrm{G}), \gamma_{\text {cens }}^{\prime}(\mathrm{G})\right\}
\end{aligned}
$$

\section{Theorem 1.4.8}

A censd-set $X$ of $G$ is minimal if and only if for each edge $e \in X$, one of the following conditions is satisfied.

i. There exist an edge $f \in E \backslash X$ such that $N(f) \cap X=\{e\}$.

ii. $e$ is an isolated edge in $\langle X\rangle$ and

iii. $\mathrm{N}(\mathrm{e}) \cap(\mathrm{E} \backslash \mathrm{X})=\phi$

\section{Proof}

Let $\mathrm{X}$ be a CENSD-set of G. Assume that $\mathrm{X}$ is minimal. Therefore, $X-\{g\}$ is not a CENSD-set for any $g \in X$. Now to prove that any one of the above three conditions is satisfied. On the contrary, if there exists an edge e $\in X$ such that e does not satisfy any of the given conditions then $\mathrm{X}^{\prime}=\mathrm{X}$ $\{\mathrm{e}\}$ is an ED-set of G. Also $\mathrm{N}(\mathrm{e}) \cap(\mathrm{E} \backslash \mathrm{X}) \neq \phi$ gives $\left\langle\mathrm{E} \backslash \mathrm{X}^{\prime}\right\rangle$ is connected. This implies that $\mathrm{X}^{\prime}$ is a CENSD-set of G, which contradict the minimality of $\mathrm{X}$. This proves the necessity.
Conversely, for connected $G$ if any one of the given three conditions is satisfied gives the sufficiency.

Next, we obtained a relationship between $\gamma_{\text {cens }}^{\prime}(H)$ and $\gamma^{\prime}$ cens $(G)$, where $H$ is any spanning connected subgraph of $\mathrm{G}$.

\section{Theorem 1.4.9}

For the graph $\mathrm{G}$ which is not a cycle graph with atleast 5 vertices, then $\gamma_{\text {cens }}^{\prime}(\mathrm{G}) \leq \gamma_{\text {cens }}^{\prime}(\mathrm{H})$ where $\mathrm{H}$ is any spanning connected subgraph of $\mathrm{G}$

\section{Proof}

Since $\mathrm{G}$ is connected then any spanning tree $\mathrm{T}$ of $\mathrm{G}$ is the minimal connected subgraph of $\mathrm{G}$ such that $\gamma_{\text {cens }}^{\prime}(\mathrm{G}) \leq$ $\gamma_{\text {cens }}^{\prime}(\mathrm{T}) \leq \gamma_{\text {cens }}^{\prime}(\mathrm{H})$ and hence the result. standard graphs.

Here, we listed the exact values of $\gamma_{\text {cens }}^{\prime}$ for some

\section{Propositions 1.4.10}

i. For any complete graph $\mathrm{K}_{\mathrm{n}}$ with $\mathrm{n} \geq 3$

$\gamma_{\text {cens }}^{\prime}\left(K_{n}\right)=\gamma_{\text {cens }}^{\prime}\left(K_{n}\right)=\mathrm{n} / 2$

ii. For any complete bipartite graph $\mathrm{K}_{\mathrm{m}, \mathrm{n}}$ with $2 \leq \mathrm{m} \leq \mathrm{n}$,

$\gamma_{\text {cens }}^{\prime}\left(K_{\mathrm{m}, \mathrm{n}}\right)=\gamma_{\text {cens }}^{\prime}\left(\mathrm{K}_{\mathrm{m}, \mathrm{n}}\right)=\gamma^{\prime}\left(\mathrm{K}_{\mathrm{m}, \mathrm{n}}\right)=\min \{\mathrm{m}, \mathrm{n}\}$ and

$\gamma_{\text {cens }}^{\prime}\left(\mathrm{K}_{1, \mathrm{n}}\right)=1, \mathrm{n} \geq 1$.

iii. For any cycle graph $\mathrm{C}_{\mathrm{n}}, \mathrm{n} \geq 3$

$\gamma_{\text {cens }}^{\prime}\left(\mathrm{C}_{\mathrm{n}}\right)=\mathrm{n}-2=\gamma_{\mathrm{c}}^{\prime}\left(\mathrm{C}_{\mathrm{n}}\right)$

iv. For any wheel graph $\mathrm{W}_{\mathrm{n}}, \mathrm{n} \geq 3$

$\gamma_{\text {cens }}^{\prime}\left(\mathrm{W}_{\mathrm{n}}\right)=\left\{\begin{array}{l}{\left[\frac{\mathrm{n}+1}{3}\right\rceil, \mathrm{n} \equiv 0 \bmod 3} \\ \left\lceil\frac{\mathrm{n}}{3}\right], \mathrm{n} \equiv 1,2 \bmod 3\end{array}\right\}$

v. For any path graph $\mathrm{P}_{\mathrm{n}}, \mathrm{n} \geq 3$

$\gamma_{\text {cens }}^{\prime}\left(P_{n}\right)=\left\{\begin{array}{l}n-3, n \geq 5 \\ n-2, n=3,4\end{array}\right\}$

vi. For any fan graph $F_{n}, n \geq 3$

$\gamma_{\text {cens }}^{\prime}\left(F_{n}\right)=\left\lceil\frac{\mathrm{n}}{3}\right\rceil$

vii. For any book graph $\mathrm{B}_{\mathrm{n}}$

$\gamma_{\text {cens }}^{\prime}\left(\mathrm{B}_{\mathrm{n}}\right)=\left\{\begin{array}{l}\mathrm{n}, \mathrm{n} \geq 2 \\ 2, \mathrm{n}=1\end{array}\right\}$

viii. For one point union of $\mathrm{t}$ cycles of length $\mathrm{n}$ graph $\mathrm{C}_{\mathrm{n}}{ }^{(\mathrm{t})}$, $\mathrm{t} \geq 1$ (Joseph A. Gallian, 2008)

$\gamma_{\text {cens }}^{\prime}\left(C_{n}{ }^{(t)}\right)=\left\{\begin{array}{l}(n-4) t+2, n \geq 5 \\ t+1, n=4 \\ t, n=3\end{array}\right\}$

ix. For any triangular snake graph $\mathrm{mC}_{3}, \mathrm{~m} \geq 1[8]$ 


$$
\gamma_{\text {cens }}^{\prime}\left(\mathrm{mC}_{3}\right)=\left\{\begin{array}{l}
\frac{2}{3} \mathrm{~m}, \mathrm{~m} \equiv 0 \bmod 3 \\
\left\lfloor\frac{\mathrm{m}}{3}\right\rfloor+\left\lceil\frac{\mathrm{m}}{3}\right\rfloor, \mathrm{m} \equiv 1 \bmod 3 \\
\left\lceil\frac{\mathrm{m}}{2}\right\rfloor+\left\lfloor\frac{\mathrm{m}}{4}\right\rfloor, \mathrm{m}=2 \bmod 3
\end{array}\right\}
$$

\section{Theorem 1.4.11}

For any graph $\mathrm{G}, \gamma_{\text {cens }}^{\prime}(\mathrm{G}) \leq \mathrm{m}-\omega^{\prime}(\mathrm{G})+1$ where $\omega^{\prime}(\mathrm{G})$ denote the size of the largest complete subgraph of $G$ and $m$ is the size of the graph G.

\section{Proof}

Let $\mathrm{Y}$ be a set of edges of $\mathrm{G}$ such that $\langle\mathrm{Y}\rangle$ is complete with $|\mathrm{Y}|=\omega^{\prime}(\mathrm{G})$. Then for any e $\in \mathrm{Y},(\mathrm{E} \mid \mathrm{Y}) \cup\{\mathrm{e}\}$ is a CENSD-set of $G$ and hence $\gamma_{\text {cens }}^{\prime}(G) \leq \mid E \backslash Y \cup\{\mathrm{e}\}$. That is, $\gamma_{\text {cens }}^{\prime}(\mathrm{G}) \leq \mathrm{m}-\omega^{\prime}(\mathrm{G})+1$

\section{Theorem 1.4.12 (Arumugam and Velammal, 1998)}

For any connected unicyclic graph $\mathrm{G}=(\mathrm{V}, \mathrm{E})$ with cycle $\mathrm{C}, \gamma^{\prime}$ cens $(\mathrm{G}) \leq \mathrm{m}-\Delta^{\prime}$ if and only if one of the following holds:

i. $\mathrm{G}=\mathrm{C}_{3}$

ii. $\quad \mathrm{C}=\mathrm{C}_{3}=\left(\mathrm{u}_{1}, \mathrm{u}_{2}, \mathrm{u}_{3}, \mathrm{u}_{4}\right), \operatorname{deg}\left(\mathrm{u}_{1}\right) \geq 3, \operatorname{deg}\left(\mathrm{u}_{2}\right)=\operatorname{deg}\left(\mathrm{u}_{3}\right)=$ $2, \mathrm{~d}(\mathrm{u}, \mathrm{w}) \leq 2$ for all vertices $\mathrm{w}$ not on $\mathrm{C}$ and $\operatorname{deg}(\mathrm{w}) \geq$ 3 for at most one vertex $\mathrm{w}$ not on $\mathrm{C}$.

iii. $\mathrm{C}=\mathrm{C}_{3}=\left(\mathrm{u}_{1}, \mathrm{u}_{2}, \mathrm{u}_{3}, \mathrm{u}_{4}\right), \operatorname{deg}\left(\mathrm{u}_{1}\right) \geq 3, \operatorname{deg}\left(\mathrm{u}_{2}\right) \geq 3$, $\operatorname{deg}\left(u_{3}\right)=2$, all vertices not on $C$ adjacent to $u_{1}$ have degree at most 2 and all vertices whose distance from $\mathrm{u}_{1}$ is 2 are pendant vertices.

iv. $\mathrm{C}=\mathrm{C}_{3}, \operatorname{deg}\left(\mathrm{u}_{1}\right)=3, \operatorname{deg}\left(\mathrm{u}_{2}\right) \geq 3, \operatorname{deg}\left(\mathrm{u}_{3}\right) \geq 3$ and all vertices not on $\mathrm{C}$ are pendant vertices

v. $\mathrm{G}=\mathrm{C}_{4}$

vi. $\mathrm{C}=\mathrm{C}_{4}$, either exactly one vertex of $\mathrm{C}$ or two adjacent vertices of $\mathrm{C}$ have degree atleast 3 and all vertices not on $\mathrm{C}$ are pendant vertices.

From Theorem 1.4.6 and Theorem 1.4.12 we have the following theorem.

\section{Theorem 1.4.13} cycle c,

For any connected unicyclic graph $\mathrm{G}=(\mathrm{V}, \mathrm{E})$ with

$\gamma^{\prime}$ cens $(\mathrm{G}) \geq \mathrm{m}-\Delta^{\prime}$ if and only if one of the subdivision in Theorem 1.4.10 holds.

\section{Theorem 1.4.14}

For any graph $\mathrm{G}$ of order $\geq 3, \gamma_{\text {cens }}^{\prime}(\mathrm{G}) \leq \mathrm{n}-2$. Further for cyclic graphs the equality holds.

\section{Proof}

Since $\mathrm{G}$ is connected there is a spanning tree $\mathrm{T}$ of $\mathrm{G}$ with $n-1$ edges. If $x$ is a pendant edge of $T$ then $n-2$ edges of $T$ other than $\mathrm{x}$ form a maximum co-edge non-split dominating set of $\mathrm{G}$, hence $\gamma_{\text {cens }}^{\prime}(\mathrm{G}) \leq \mathrm{n}-2$. Also, the equality can be attained for $\mathrm{C}_{\mathrm{n}}, \mathrm{n} \geq 3$.

\section{Theorem 1.4.15}

If $G$ is a subdivision of star graph then $\gamma_{\text {cens }}^{\prime}(G)=m$ $\beta_{1}$, where $\beta_{1}$ is the edge independence number of $G$ and $m$ is the size of the graph G.

\section{Proof}

Let $\mathrm{G}$ be a subdivision of the star graph $K_{1, n} n \geq 1$. Then $\beta_{1}=$ n. From the edge set of $G$, if we remove all these $\beta_{1}$ edges form the minimum CENSD-set of G. Hence $\gamma_{\text {cens }}^{\prime}(\mathrm{G})$ $=\mathrm{m}-\beta_{1}$.

\section{Theorem 1.4.16}

If $\lambda(G)>\beta_{1} G$ then $\gamma_{\text {cens }}^{\prime}(G)=\gamma^{\prime}(G)$ where $\lambda(G)$ is the edge connectivity of $\mathrm{G}$.

\section{Proof}

Let $X$ be a $\gamma^{\prime}$-set of $G$. Since $\lambda(G)>\beta_{1} G \geq \gamma^{\prime}(G)$, implies that $\langle E \backslash X\rangle$ is connected. This proves that $X$ is a $\gamma^{\prime}{ }^{\prime}$ cens set of G. Hence $\gamma_{\text {cens }}^{\prime}(G)=\gamma^{\prime}(G)$.

\section{Theorem 1.4.17}

Let $\mathrm{X}$ be a $\gamma_{\text {cens }}^{\prime}$-set of G. If no two edges in ElX are adjacent to a common edge in $X$ then $\gamma_{\text {cens }}^{\prime}(G)+\epsilon^{\prime}(T) \geq m$ where $\epsilon^{\prime}(\mathrm{T})$ is the maximum number of pendant edges in any spanning tree $\mathrm{T}$ of $\mathrm{G}$ and $\mathrm{m}$ is the size of the graph $\mathrm{G}$.

\section{Proof}

Let $\mathrm{X}$ be a $\gamma^{\prime}$ cens $^{-}$-set of $\mathrm{G}$. Assume that if any two edges $e_{1}, f_{1}$ in $E \backslash X$ and $e_{2}, f_{2}$ in $X$ such that $e_{2}$ is adjacent to $e_{1}$ but not to $f_{1}$ and $f_{2}$ is adjacent to $f_{1}$ but not to $e_{2}$, this implies that there exists a spanning tree $\mathrm{T}$ of $\langle\mathrm{E} \backslash \mathrm{X}\rangle$ in which each edge of EIX is adjacent to an edge of $X$. This proves that $\epsilon^{\prime}(T) \geq|E \backslash X|$. That is, $\epsilon^{\prime}(T) \geq m-\gamma_{\text {cens }}^{\prime}(G)$.

\section{Theorem 1.4.18}

If $\delta^{\prime}(\mathrm{G})+\omega^{\prime}(\mathrm{G}) \geq \mathrm{m}+1$ then $\gamma_{\text {cens }}^{\prime}(\mathrm{G})+\gamma_{\mathrm{c}}^{\prime}(\mathrm{G}) \leq \mathrm{m}$ where $\delta^{\prime}(\mathrm{G})$ is the minimum edge degree of $\mathrm{G}, \omega^{\prime}(\mathrm{G})$ the size of the largest complete subgraph of $G$ and $m$ is the size of the graph G.

\section{Proof}

Let $\mathrm{X}$ be a $\gamma_{\text {cens }}^{\prime}$-set of G. By Theorem 1.4.11 we have $\gamma^{\prime}$ cens $(\mathrm{G}) \leq \omega^{\prime}(\mathrm{G})+1$ and by using given hypothesis, we get $\gamma_{\text {cens }}^{\prime}(\mathrm{G}) \leq \delta^{\prime}(\mathrm{G})$. Then every edge in $\mathrm{X}$ is adjacent to some edge in ElX gives ElX is an ED-set of G. Since $\langle E \mid X\rangle$ is connected gives EIX is a CED-set of $\mathrm{G}$ and hence $\gamma_{c}^{\prime}(\mathrm{G}) \leq$ $|E \backslash X|=m-\gamma_{\text {cens }}^{\prime}(G)$. Hence the theorem.

\section{Theorem 1.4.19}

For any tree $\mathrm{T}$, if $\mathrm{X}$ is a $\gamma_{\text {cens }}^{\prime}$-set and $\mathrm{m}^{1}, \mathrm{n}^{1}$ are the number of non-pendant and pendant edges of $\mathrm{T}$ in $<\mathrm{EIX}$. respectively then 


$$
\gamma_{\text {cens }}^{\prime}(T)=\left\{\begin{array}{ll}
=\mathrm{q}-\mathrm{m}^{1}-\mathrm{n}^{1} & \text { if } \mathrm{n}^{1}<|E \backslash X|, \mathrm{m}^{1} \neq 0 \\
>\mathrm{q}-\mathrm{m}^{1}-\mathrm{n}^{1} & \text { if } \mathrm{n}^{1}=|\mathrm{E} \backslash X|, \mathrm{m}^{1} \neq 0 \\
<\mathrm{q}-\mathrm{n}^{1} & \text { if } \mathrm{n}^{1}<|E \backslash X|, \mathrm{m}^{1}=0 \\
=\mathrm{q}-\mathrm{n}^{1} & \text { if } \mathrm{n}^{1}=|E \backslash X|, \mathrm{m}^{1}=0
\end{array}\right\}
$$

\section{Proof}

Let $\mathrm{X}$ be $\gamma_{\text {cens }}^{\prime}$-set of $\mathrm{T}$. Let $\mathrm{m}^{1}$ and $\mathrm{n}^{1}$ be denote number of non-pendant and pendant edges of $\mathrm{T}$ in $\langle\mathrm{E} \mid \mathrm{X}\rangle$ respectively.

\section{Case (i)}

$\mathrm{n}^{1}<|\mathrm{E} \backslash \mathrm{X}|$ and $\mathrm{m}^{1} \neq 0$. Then E\X has atleast one non-pendant edge of $\mathrm{T}$ and $\langle\mathrm{E} \mid \mathrm{X}\rangle$ is connected gives every non-pendant edge in $\angle \mathrm{EIX}$. is a bridge of $\mathrm{T}$. Let $\mathrm{S}$ be a set of bridges which are adjacent to pendant edges of $\mathrm{T}$ with $|\mathrm{S}|=\mathrm{m}^{1}$. Then

$|E \backslash X|=|S|+n^{1}=m^{1}+n^{1}$. Hence $\gamma_{\text {cens }}^{\prime}(T)=|X|=m-m^{1}-n^{1}$.

\section{Case (ii)}

$n^{1}=|E \backslash X|$ and $m^{1} \neq 0$. Then all the edges in $E \backslash X$ are pendant edges of $\mathrm{T}$ and $\mathrm{m}^{1}>0$. Therefore $|\mathrm{E} \backslash \mathrm{X}|<\mathrm{m}^{1}+\mathrm{n}^{1}$. Hence $\gamma_{\text {cens }}^{\prime}(G)=|X|>m-m^{1}-n^{1}$.

\section{Case (iii)}

$$
\mathrm{n}^{1}=|\mathrm{E} \backslash \mathrm{X}| \text { and } \mathrm{m}^{1}=0 \text {. Then } \gamma_{\text {cens }}{ }^{\prime}(\mathrm{G})=|\mathrm{X}|=\mathrm{q}-
$$$$
|\mathrm{E} \backslash \mathrm{X}|=\mathrm{m}-\mathrm{n}^{1} \text {. }
$$

\section{Case (iv)} $m-n^{1}$.

$$
\mathrm{n}^{1}<|\mathrm{E} \backslash \mathrm{X}| \text { and } \mathrm{m}^{1}=0 \text {. Then } \gamma_{\text {cens }}{ }^{\prime}(\mathrm{G})=|\mathrm{X}|<
$$

\section{Theorem 1.4.20: (Arumugam and Velammal 1998)}

For any tree $T, \gamma_{c}^{\prime}(T)=q_{1}$, where $q_{1}$ is the maximum number of bridges of $\mathrm{T}$. relation.

By using the above theorem, we have the following

\section{Theorem 1.4.21} then equality holds.

For any tree $\mathrm{T}, \gamma_{c}^{\prime}(\mathrm{T}) \leq \gamma_{\text {cens }}^{\prime}(\mathrm{T})$. Further if $\mathrm{T}$ is a path

\section{Proof}

If $\mathrm{T}$ has no bridge then $\mathrm{T}=\mathrm{P}_{3}$ and hence $\gamma_{c}^{\prime}(\mathrm{T})=$ $\gamma^{\prime}$ cens $(T)=1$. Let $S$ be the set of all bridges of $T$ with $|S|=q_{1}$ and $S_{1} \subseteq S$ the set of all bridges such that each edge of $S_{1}$ is adjacent to a pendant edge with $\left|\mathrm{S}_{1}\right|=\mathrm{q}_{2}$. Thus $\mathrm{E}(\mathrm{T})=\mathrm{q}>$ $\mathrm{q}_{1}+\mathrm{q}_{2}$. By Theorem 1.4.20, we have $\gamma_{\mathrm{c}}^{\prime}(\mathrm{T})=\mathrm{q}_{1}$. Hence $\gamma_{\mathrm{c}}^{\prime}(\mathrm{T}) \leq$ $\gamma^{\prime}$ cens $(T)$. If $\mathrm{T}$ is a path with $\mathrm{n} \geq 5$ vertices then $\gamma_{c}^{\prime}(\mathrm{T})=\gamma_{\text {cens }}^{\prime}(\mathrm{T})$.

\section{Theorem 1.4.22}

For any tree $\mathrm{T}, \gamma_{\text {cens }}{ }^{\prime}(\mathrm{T}) \leq \max _{\mathrm{e} \in \mathrm{E}(\mathrm{T})}\{\operatorname{deg}(\mathrm{e})-|\mathrm{S}(\mathrm{e})|\}+1$ where $\mathrm{S}(\mathrm{e})$ is the set of all pendant edges adjacent to e and $\mathrm{m}$ is the size of the graph $\mathrm{G}$.

\section{Proof}

Let e be an edge such that $\operatorname{deg}(\mathrm{e})-|\mathrm{S}(\mathrm{e})|$ being maximum. Then $\{\mathrm{E} \backslash\{\mathrm{N}[\mathrm{e}] \backslash \mathrm{S}(\mathrm{e})\}\} \cup\{\mathrm{f}\}$ where $\mathrm{f} \in \mathrm{N}(\mathrm{e})$ is a CENSD-set of $\mathrm{T}$ and hence the result.

\section{Corollary 1.4.23}

For any tree $\mathrm{T}, \gamma_{\text {cens }}^{\prime}(\mathrm{T}) \leq \mathrm{m}-\Delta^{\prime}(\mathrm{T})+\mathrm{q}_{0}+1$, where $\Delta^{\prime}(\mathrm{T})$ is the maximum edge degree of $\mathrm{T}, \mathrm{q}_{0}$ is the minimum number of pendant edges adjacent to an edge of maximum degree and $\mathrm{m}$ is the size of the graph $\mathrm{G}$.

\section{Proof}

Since for any e in $E(T), \operatorname{deg}(e) \leq \Delta^{\prime}(T)$ and for the set of all pendant edges adjacent to e denoted by $S(e),|S(e)| \geq q_{0}$ gives the result by using the previous Theorem 1.4.22.

\section{Corollary 1.4.24}

For the graph $\mathrm{G}$ which is not a cycle graph with atleast 5 vertices, $\gamma_{\text {cens }}^{\prime}(\mathrm{G}) \leq \mathrm{m}-\max _{\mathrm{e} \in \mathrm{E}(\mathrm{T})}\{\operatorname{deg}(\mathrm{e})-|\mathrm{S}(\mathrm{e})|\}+1$ where $\mathrm{S}(\mathrm{e})$ is the set of all edges which are adjacent to e but not adjacent to any edge of $\mathrm{E} \backslash \mathrm{N}(\mathrm{e})$.

\section{Proof}

Since $\mathrm{G}$ is connected then there exists a spanning tree $\mathrm{T}$ such that $\gamma_{\text {cens }}^{\prime}(\mathrm{G}) \leq \gamma_{\text {cens }}^{\prime}(\mathrm{T})$ by using Theorem 1.4.9. Then the result follows from Theorem 1.4.22.

- We established Nordhaus-Gaddum type results for the coedge non-split domination number.

\section{Theorem 1.4.25}

If $\mathrm{G}$ and $\overline{\mathrm{G}}$ are connected complementary graphs, then

(i) $\gamma_{\text {cens }}(\mathrm{G})+\gamma_{\text {cens }}(\overline{\mathrm{G}}) \leq 2(\mathrm{n}-2)$ and

(ii) $\gamma_{\text {cens }}{ }^{\prime}(\mathrm{G}) \cdot \gamma_{\text {cens }}(\overline{\mathrm{G}}) \leq(\mathrm{n}-2)^{2}$

Further there exists a graph $\mathrm{G}$ for which equality holds.

\section{Proof}

The results follows from Theorem 1.4.14 and equality is attained for $\mathrm{C}_{5}$.

\section{Theorem 1.4.26} of $\mathrm{G}$.

If $\mathrm{X}$ is a minimal ED-set of $\mathrm{G}$ then ElX is an ED-set

\section{Proof}

Let $\mathrm{f}$ be any edge of $\mathrm{X}$. If $\mathrm{f}$ is not adjacent to some edge of $\mathrm{EIX}$ and since $\mathrm{G}$ has no isolated edges, $\mathrm{f}$ is adjacent to some edge $g$ in $X$; in this case $X \backslash\{f\}$ is an ED-set which contradicts the minimality of X. Hence EIX is an ED-set of G.

- The following is an example to show that if $\mathrm{X}$ is an ED-set of G then EIX need not be an ED-set of G. 
G:

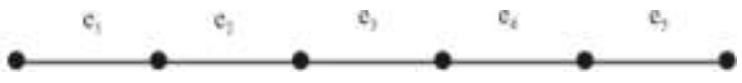

Graph G : Figure 4.

Here $X=\left\{e_{2}, e_{3}, e_{4}\right\}$ is an ED-set of $G$ but $E I X=$ $\left\{\mathrm{e}_{1}, \mathrm{e}_{5}\right\}$ is not an ED-set of $\mathrm{G}$.

\section{Theorem 1.4.27}

Every edge of a graph is a minimal ED-set if and only if the graph is a star graph.

\section{Proof}

Since every edge of a graph is a minimal ED-set of G implies every other edge of $G$ must be adjacent to each other, hence $G$ must be a star graph. The converse follows immediately

\section{Definition 1.4.28}

An edge dominating set $\mathrm{X}$ is said to be an independent edge dominating set (IED-set) if no two edges in $\mathrm{X}$ are adjacent. The independent edge domination number $\gamma_{\mathrm{i}}(\mathrm{G})$ of $\mathrm{G}$ is the minimum cardinality taken over all IED-sets of $\mathrm{G}$.

\section{Proposition 1.4.29}

For any graph $\mathrm{G}, \mathrm{V}((\mathrm{E} \backslash \mathrm{X}))=\mathrm{V}(\mathrm{G})$ if and only if $\mathrm{X}$ is an independent set of edges of $\mathrm{G}$.

\section{Theorem 1.4.30}

If $\mathrm{X}$ is an IED-set of $\mathrm{G}$ then $\mathrm{X}$ is both a minimal EDset and a maximal independent set. Conversely, if $\mathrm{X}$ is a maximal independent set then $\mathrm{X}$ is an IED-set of $\mathrm{G}$.

\section{Proof}

Let $\mathrm{X}$ be an IED-set of $\mathrm{G}$. If we take any edge out of $X$ then this edge is not adjacent to any one of the remaining edges of $\mathrm{X}$ and hence $\mathrm{X}$ is a minimal ED-set of G. Since $\mathrm{X}$ is an IED-set, it cannot be enlarged further as an independent set and hence $\mathrm{X}$ is a maximal independent set of G. Conversely, for any $\mathrm{f} \in \mathrm{ElX}$, it should be adjacent to atleast one edge in $\mathrm{X}$; otherwise $\mathrm{X}$ can be enlarged further as an independent set, which is a contradiction and hence the result.

The following is an example to show that a minimal ED-set need not be an independent set of edges.

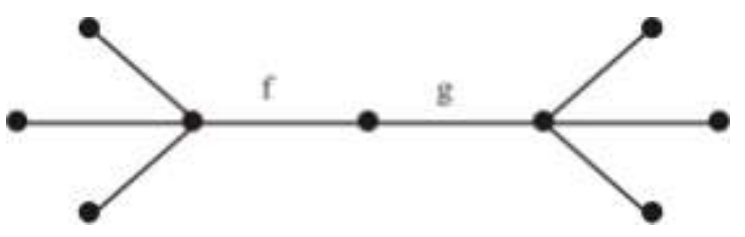

Graph G : Figure 5.

For this graph $X=\{f, g\}$ is an ED-set of $G$ but it is not an independent set.

\section{Theorem 1.4.31}

For any graph $\mathrm{G}$, (i) $\gamma_{\mathrm{cs}}{ }^{\prime}(\mathrm{G}) \leq \alpha_{1}(\mathrm{G})$ where $\alpha_{1}(\mathrm{G})$ is the edge covering number of $\mathrm{G}$.

\section{Proof}

Let $\mathrm{X}$ be a maximum independent set of edges in $\mathrm{G}$. Then $\mathrm{X}$ has atleast two edges and every edge in $\mathrm{X}$ adjacent to some edge in ElX. This implies that ElX is a CESD-set of G and hence the result.

We presented without proof a straightforward result that characterized ED-sets of G that are CESD-sets of G.

\section{Theorem 1.4.32}

An ED-set $X$ is a CESD-set if and only if there exist two vertices $\mathrm{x}_{1}, \mathrm{x}_{2}$ in $\mathrm{V}\left(\langle\mathrm{E} \mid \mathrm{X}\rangle_{\mathrm{G}}\right)$ such that every pair $\mathrm{P}\left(\mathrm{x}_{1}, \mathrm{x}_{2}\right)$ contains an edge of $\mathrm{X}$.

\section{Theorem 1.4.33}

A CESD-set of $\mathrm{G}$ is minimal if and only if for each edge $\mathrm{f}$ in $\mathrm{X},<(\mathrm{E} \mid \mathrm{X}) \cup\{\mathrm{f}\}>_{\mathrm{G}}$ is connected.

\section{Theorem 1.4.34}

For any graph $\mathrm{G}, \gamma_{\mathrm{cs}}^{\prime}(\mathrm{G}) \geq \mathrm{m}-\mathrm{n}+2$

\section{Proof}

Let $\mathrm{X}$ be a $\gamma_{c s}^{\prime}(\mathrm{G})$-set.

\section{Case(i)}

Let $X$ be an independent set. Since $\langle E(G) \backslash X\rangle$ is disconnected, the subset EIX has less than n-1 edges and hence $X$ has greater than $m-n+1$ edges, hence the result.

\section{Case(ii)}

Let $\mathrm{X}$ be non-independent set. Take $\mathrm{n}_{1}=\left|\mathrm{V}\langle\mathrm{E} \backslash \mathrm{X}\rangle_{\mathrm{G}}\right|<\mathrm{n}$, then $|\mathrm{E}| \mathrm{X} \mid<\mathrm{n}_{1}-1$, hence $\gamma^{\prime}{ }_{\mathrm{cs}}(\mathrm{G})=|\mathrm{X}| \geq \mathrm{m}$ $\mathrm{n}_{1}+1>\mathrm{m}-\mathrm{n}+1$ and hence the theorem.

The exact values of $\gamma^{\prime} \mathrm{cs}(\mathrm{G})$ for several classes of graphs are given below.

\section{Proposition 1.4.35}

i. For the cycle $C_{n}, n \geq 3, \gamma^{\prime}{ }_{\text {cs }}\left(C_{n}\right)=\left\lceil\frac{n}{3}\right\rceil$

ii. For the complete bipartite graph $\mathrm{K}_{\mathrm{m}, \mathrm{n}}, \mathrm{m}>1, \mathrm{n}>1$.

$$
\gamma^{\prime}{ }_{\mathrm{cs}}\left(\mathrm{K}_{\mathrm{m}, \mathrm{n}}\right)=(\mathrm{m}-1) \mathrm{n}
$$

iii. For the path graph $P_{n}, n \geq 3$,

$$
\gamma^{\prime}{ }_{\text {cs }}\left(P_{n}\right)=\left\{\begin{array}{l}
\left\lfloor\frac{n}{3}\right\rfloor \text { if } n \equiv 1(\bmod 3) \\
\left\lceil\frac{n}{3}\right\rceil \text { if } n \equiv 0,2(\bmod 3)
\end{array}\right\}
$$

iv. For the fan graph $F_{n}, n \geq 3, \gamma^{\prime}{ }_{c s}\left(F_{n}\right)=n$

v. For the book graph $B_{n}, n \geq 1, \gamma_{c s}^{\prime}\left(B_{n}\right)=n+1$

vi. For the wheel graph $\mathrm{W}_{\mathrm{n}}, \mathrm{n} \geq 3, \gamma^{\prime}{ }_{\mathrm{cs}}\left(\mathrm{W}_{\mathrm{n}}\right)=\mathrm{n}+1$

\section{Lemma 1.4.36}

For any graph $\mathrm{G}$, a subset $\mathrm{X}$ of $\mathrm{E}$ is an $\mathrm{ED}$-set of $\mathrm{G}$ if and only if $\mathrm{N}_{\mathrm{G}}(\mathrm{f}) \cap \mathrm{X} \neq \phi$ for every $\mathrm{f} \in \mathrm{E} \backslash \mathrm{X}$. 


\section{Proof}

Assume that $\mathrm{X}$ is an $\mathrm{ED}$-set of $\mathrm{G}$ and $\mathrm{f} \in \mathrm{E} \backslash \mathrm{X}$. Then there exist an edge $g$ in $X$ such that $g \in N_{G}(f)$ and hence the necessary part. On the other hand, suppose for every $f \in E \backslash X$, $\mathrm{N}_{\mathrm{G}}(\mathrm{f}) \cap \mathrm{X} \neq \phi$ then for an edge $\mathrm{g} \notin \mathrm{X}, \mathrm{N}_{\mathrm{G}}(\mathrm{g}) \cap \mathrm{X} \neq \phi$. It implies that there exist an edge $f$ in $\mathrm{N}_{\mathrm{G}}(\mathrm{g}) \cap \mathrm{X}$ such that $\mathrm{f}$ and $\mathrm{g}$ are adjacent and hence $f \in X$. It shows that $X$ is an ED-set of $G$ and hence the proof.

\section{Theorem 1.4.37}

Let $\mathrm{X}$ be a CESD-set of $\mathrm{G}$ and $\mathrm{k} \in \mathrm{X}$ such that $\mathrm{N}_{\mathrm{G}}(\mathrm{k})$ $\subseteq X$. Then $X-\{k\}$ is a CESD-set in $G$.

\section{Proof}

Let $\mathrm{X}$ be a CESD-set of G. First, we shall prove that $X-\{k\}$ is an ED-set of $G$. For, let $f \in\{E(G) \backslash X\} \cup\{k\}$. As $k$ $\in X, f$ cannot be equal to $k$. Therefore $f \in E(G) \backslash X$ then there exist $g \in X$ such that $g \in N_{G}(f)$. Again $f \in E(G) \backslash X, g \neq k$ implies $\mathrm{g} \in \mathrm{X} \backslash \mathrm{k}$. Because $\mathrm{N}_{\mathrm{G}}(\mathrm{k}) \subseteq \mathrm{X}$, $\mathrm{k}$ becomes an isolated edge in $\{E(G) \backslash X\} \cup\{k\}$. Thus $X \backslash\{k\}$ is a CESD-set in G.

- The graph obtained from $\mathrm{G}$ by subdividing each edge of $\mathrm{G}$ exactly once is called the subdivision graph of $\mathrm{G}$.

\section{Theorem 1.4.38}

For any tree $\mathrm{T} \neq \mathrm{K}_{1, \mathrm{n}}, \mathrm{n} \geq 1, \gamma^{\prime}(\mathrm{T})=\gamma_{\mathrm{cs}}^{\prime}(\mathrm{T})$.

\section{Proof} result follows.

Since every edge of tree is a bridge and hence the

\section{Theorem 1.4.39}

For any tree $\mathrm{T} \neq \mathrm{K}_{1, \mathrm{n}}$ of order $\mathrm{n}>2, \gamma_{\text {cs }}^{\prime}(\mathrm{G}) \leq(\mathrm{n}-1) / 2$; equality holds if and only if $\mathrm{T}$ is isomorphic to the subdivision of a star graph.

\section{Proof}

The result follows from Theorem $\gamma^{\prime}(\mathrm{G}) \leq(\mathrm{n}-1) / 2$ when $\mathrm{G}$ is a tree $\mathrm{T}$ of order $\mathrm{n}>2$ (Arumugam and Velammal 1998).

\section{Theorem 1.4.40}

G-e.

If $\mathrm{X}$ is an ED-set of $\mathrm{G}$ if and only if $\mathrm{X}$ is an ED-set of

\section{Proof}

The necessary part follows from Lemma 2.4.36, since there exist an edge $g$ different from e such that $g$ is in $\mathrm{N}_{\mathrm{G}-\mathrm{e}}(\mathrm{f}) \cap$ $X$, for every $f \in E \backslash X$. On the other hand, if $X$ is not an ED-set of $\mathrm{G}$ then for e not in $\mathrm{X}, \mathrm{N}_{\mathrm{G}-\mathrm{e}}(\mathrm{e}) \cap \mathrm{X}=\phi$, which contradicts the fact that $\mathrm{X}$ is an ED-set of G-e and hence the proof.

- We studied the behaviour of this inverse domination parameter after the deletion of an edge from the graph $\mathrm{G}$.

\section{Theorem 1.4.41}

Let $X$ be a CESD-set of $G$ and $e=\{x, y\}$ not an isolated edge in $E(G) \backslash X$. Suppose $d, f$ are any two edges of $G$ such that $\mathrm{d}$ is incident with $\mathrm{x}$ and $\mathrm{f}$ is incident with $\mathrm{y}$ then $\mathrm{X}$ is a CESDset of G-e.

\section{Proof}

Since $\mathrm{X}$ is a CESD-set in G, we have $\mathrm{X}$ is an ED-set in $\mathrm{G}$ and for every $\mathrm{h} \in \mathrm{ElX}$ such that $\mathrm{N}_{\mathrm{G}}(\mathrm{h}) \cap \mathrm{X} \neq \phi$. Moreover, $\mathrm{N}_{\mathrm{G}-\mathrm{e}}(\mathrm{h}) \cap \mathrm{X} \neq \phi$ since $\mathrm{d}, \mathrm{f} \in \mathrm{X}$. It means that $\mathrm{X}$ is an ED-set in G-e. Now to prove $\langle\mathrm{E}(\mathrm{G}) \mid \mathrm{X}\rangle_{\mathrm{G}-\mathrm{e}}$ is disconnected. Since $\langle E(G) \mid X\rangle_{G}$ is disconnected implies that there exist an edge $g \in E(G) \backslash X$ such that every path $P_{G}\left(x_{1}, x_{2}\right), x_{1}, x_{2} \in V(E(G)$ $\backslash \mathrm{X})$ contains no edge from $\mathrm{X}$. Also, the removal of the edge $\mathrm{e}$ from $G$ does not change the above relationship and hence the subgraph $\langle\mathrm{E}(\mathrm{G}) \backslash \mathrm{X}\rangle_{\mathrm{G}-\mathrm{e}}$ is also disconnected. This completes the proof.

\subsection{CONCLUSION}

Graph theory serves as a model for any binary relation. In domination, both dominating sets and their inverses have important roles to play. Whenever, D is a dominating set, V-D is also a dominating set. In an information retrieval system, we always have a set of primary nodes to pass on the information. In case, the system fails, we have another set of secondary nodes, to do the job in the complement. When the complement set is connected, then there will be flow of information among the members of the complement. Thus, the dominating sets and the elements in the inverse dominating sets can stand together to facilitate the communication process. They play very vital role in coding theory, computer science, operations research, switching circuits, electrical networks etc.

Thus in this paper, we defined the notions of inverse split and non split domination in graphs. We got many bounds on inverse split and non split domination numbers. NordhausGaddum type results are also obtained for these new parameters. Edge analog of these two parameters are also discussed in a detailed manner.

\subsection{REFERENCES}

[1] Ameenal Bibi, K. and Selvakumar, R (2008). The Inverse split and non-split domination numbers in graphs. Proc. of the International Conference on Mathematics and Computer Science, ICMCS 2008, Dept. of Mathematics, Loyola College, Chennai - 600 034. July 25-26.

[2] Ameenal Bibi, K. and Selvakumar, R (2009). The Inverse strong non-split r-domination number of a graph. Proc. of the National Conference on Industrial Applications of Mathematics, NCMA 2009, PG and Research Dept. of Mathematics, Sacred Heart College (Autonomous) Tirupattur, Vellore Dist., March 12-13.

[3] Ameenal Bibi, K. and Selvakumar, R (2010). The inverse strong non-split $r$-domination number of a graph - International Journal of Engineering, science and Technology, Vol.2, No. 1, pp. 127-133.; www.ijest_ng.com, ISSN No. for IJEST:

For printed version : 2141-2820

For online version : 2141-2839.

[4] Arumugam, S. and Velammal, S. (1998). Edge domination in graphs, Taiwanese Journal of Mathematics, Vol. 2, No. 2, pp. 173-179.

[5] Chartrand G. and Lesniak L. (1996). Graphs and Digraphs. Chapman and Hall / CRC.

[6] Chartrand G. and Schuster S. (1974). On the independence number of complementary graphs. 
Trans. of the New York Acad. of Sci. Series II, 36 No. 3 pp. 247-251.

[7] Cockayne, E.J. and Hedetniemi S.T. (1977). Towards a theory of domination in graphs. Networks, 7. pp. 241-267.

[8] Cockayne, E.J., Dawes R.M. and Hedetniemi S.T. (1980). Total domination in Graphs. Networks, Vol. 10. pp. 211-219.

[9] Domke G.S., Dunbar J.E. and Markus L.R (2007). The Inverse domination number of a graph, Feb' (2007).

[10] Haynes, T.W., Hedetniemi S.T. and Slater P.J. (1998). Domination in Graphs : Advanced Topics, Marcel Dekker Inc. New York, U.S.A.

[11] Haynes, T.W., Hedetniemi S.T. and Slater P.J. (1998). Fundamentals of domination in graphs, Marcel Dekker Inc. New York, U.S.A.

[12] Jayaram, S.R. (1987). Graphs and Combinatorics 3 pp. 357-363.

[13] Joseph A.Gallian, A Dynamic Survey of Graph Labeling, The Electronic Journal of Combinatorics $15,2008$.

[14] Kulli, V.R. and Sigarkanti, S.C. (1988). The connected edge domination number of a graph. Proc. R.C. Bose Mem. Conf. Abstract.
[15] Kulli, V.R. and Janakiram B. (1997). The split domination number of a graph. Graph Theory notes of New York. Newyork Academy of Sciences, XXXII. pp. 16-19.

[16] Kulli, V.R. and Janakiram B. (2000). The non-split domination number of a graph. The Journal of Pure and Applied Math. 31(5). pp. 545-550.

[17] Kulli, V.R. and Janakiram B. (2003). The strong nonsplit domination number of a graph. International Journal of Management and Systems. Vol. 19, No. 2, pp. 145-156.

[18] Kulli, V.R. and Sigarkanti S.C. (1991). Inverse domination in graphs. National Academy Science Letters, 15.

[19] Kulli, V.R., Janakiram B. and Radha Iyer R. (1999). The Cototal domination number of a graph. Journal of Discrete Mathematical Sciences and Cryptography. Vol. 2 pp. 179-185.

[20] Mitchell, S. and Hedetniemi, S.T. (1977). Edge domination in trees, Congr.Numer., pp. 489-509, 1977.

[21] Nordhaus, E.A. and Gaddum J.W. (1956). On complementary graphs. Amer.Math.Monthly, 63. pp. 175-177.

[22] Ore, O. (1962). Theory of Graphs. American Mathematical Society Colloq. Publ., Providence, RI 38 . 